\title{
DISPONIBILIDADE DE COBRE EM LODO DE CURTUME: POTENCIAL CONTAMINANTE QUÍMICO DO SOLO
}

\author{
Jéssica Taeko Sanches Kohara de Angeli ${ }^{1}$, Welliton Leandro de Oliveira Boina ${ }^{2}$, Joel Barbujiani Sigolo ${ }^{3}$ \\ ${ }^{1}$ Universidade de São Paulo - USP, Instituto de Energia e Ambiente, Mestrado em Ciência Ambiental, São Paulo, SP. \\ ${ }^{2}$ Universidade Estadual Paulista - UNESP, Presidente Prudente, SP. ${ }^{3}$ Universidade de São Paulo - USP, Instituto de \\ Geociências, São Paulo, SP.
}

\section{RESUMO}

$\mathrm{Na}$ indústria de curtimento, o lodo gerado possui componentes potencialmente tóxicos, como crômio, cobre, entre outros. Estudos indicam que disponibilizar esse lodo no solo é uma opção que minimizaria os problemas ambientais, porém as concentrações dos compostos devem estar dentro dos parâmetros determinados pela legislação. Este trabalho teve o objetivo de quantificar a concentração de cobre presente no lodo de curtume e comparar com a legislação vigente (NBR 10004) para averiguar se há risco de contaminação ambiental caso esse lodo seja disposto no solo. As amostras foram coletadas e analisadas seguindo os procedimentos descritos pelas NBR 10007 e NBR 10006, referência ao Standard Methods for the Examination of Water and Wastewater - 21a Edição. Os resultados apresentaram uma concentração de cobre na amostra de lodo acima do permitido pela legislação, sendo necessário um tratamento prévio que visa a disposição correta desse resíduo.

Palavras-chave: Poluição ambiental, resíduo industrial, metais tóxicos, couro, meio ambiente.

\section{AVAILABILITY OF COPPER IN TANNERY SLUDGE: POTENTIAL CHEMICAL SOIL CONTAMINANT}

\section{ABSTRACT}

In the tanning industry, the sludge generated has potentially toxic components, such as chromium, copper, among others. Studies indicate that making this sludge available in the soil is an option that would minimize environmental problems, but the concentrations of the compounds should be within the parameters determined by the legislation. This work aimed to quantify the concentration of copper present in the tannery sludge and compare it with the current legislation (NBR 10004) to investigate if there is risk of environmental contamination if sludge is disposed in the soil. The samples were collected and analyzed following the procedures described by NBR 10007 and NBR 10006, reference to the Standard Methods for the Examination of Water and Wastewater - 21st Edition. The results presented copper concentration in the sludge sample above that allowed by the legislation, being necessary a previous treatment that aims at the correct disposal of this residue.

Keywords: Environmental pollution, industrial waste, toxic metals, leather, environment.

\section{INTRODUÇÃO}

No processo de tratamento do efluente há geração de subprodutos sólidos e/ou semisólidos como material gradeado, areia, escuma, lodo primário e secundário. O principal subproduto em termos de volume e importância são os lodos ${ }^{1}$.
O tratamento do lodo é constituído por diversas combinações de operações e processos unitários, as principais etapas do tratamento são adensamento, estabilização, condicionamento, desidratação e disposição final. Entretanto, para lodos de curtumes, o volume do lodo é reduzido pelo do processo de adensamento, utiliza-se adensadores por gravidade, outro processo 
utilizado é a desidratação do lodo cujo objetivo é o aumento do teor de sólidos através do processo natural de leitos de secagem e para finalizar é feito a disposição final ${ }^{1}$.

A Política Nacional de Resíduos Sólidos (PNRS) permite o avanço para enfrentar os principais problemas ambientais, econômicos e sociais gerados pelo manejo inadequado dos resíduos sólidos. A classificação dos resíduos sólidos é necessária para que ocorra um gerenciamento adequado, a Norma Brasileira NBR 10004 da Associação de Normas Técnicas $(A B N T)^{2}$, classifica os resíduos quanto aos seus riscos potenciais ao meio ambiente e à saúde. As normas da ABNT, definem que, resíduos sólidos são todos os resíduos no estado semi-sólido ou sólido resultantes das atividades industriais, incluindo lodos e determinados líquidos, cujas as características tornem inviável seu lançamento na rede pública de esgotos ou corpos de água

$\mathrm{Na}$ atividade de curtimento tem-se a origem dos resíduos semi-sólidos (lodos) que são compostos por componentes orgânicos e inorgânicos ${ }^{3}$. Existem vários estudos para minimizar esses impactos, tornando o resíduo em produto, por exemplo, Araújo ${ }^{4}$ defende que o uso do lodo de curtume na agricultura é uma alternativa viável e que vários trabalhos comprovam que este resíduo do curtume é eficaz quando utilizado como fertilizante e corretivo de acidez do solo. Silva et al. ${ }^{5}$ mencionam que o processo de compostagem vem sendo proposto como uma alternativa adequada para 0 tratamento e reutilização de lodo de curtume para fins agrícolas.

Um dos maiores problemas ambientais em relação ao lodo é a sua disposição final, geralmente são aplicados no solo, o acúmulo no solo de altas concentrações de alguns elementos, como por exemplo, fenóis, sódio, crômio e cobre, geralmente contidos nesse lodo, podem proporcionar impactos negativos ao meio ambiente $^{6}$.

Alguns metais são elementos naturalmente presente nos solos, como é o caso do cobre $(\mathrm{Cu})$. O cobre é classificado como um micronutriente essencial para as plantas quando possui concentrações abaixo de $2,0 \mathrm{mg} \cdot \mathrm{L}^{-1}$, por exemplo. A forma mais comum de encontrar cobre no solo é nas estruturas cristalinas dos minerais primários e secundários, disponível na forma de sulfetos, cloretos e carbonatos, a sua disponibilidade no solo depende do $\mathrm{pH}$ e do tipo de solo, sendo que em solos arenosos a lixiviação é mais frequente do que em solos argilosos, nos quais o cobre apresenta boa fixação ${ }^{7}$.

O cobre em altas concentrações é potencialmente tóxico, a absorção excessiva desse metal em plantas pode causar distúrbios celulares nos processos de fotossíntese, respiração, pode interferir no metabolismo, comprometer a estrutura de algumas proteínas e inibir o crescimento. Para o organismo humano, o excesso de cobre tem a capacidade de interferir em alguns processos celulares, causando danos neurológicos, por exemplo ${ }^{8}$.

O objetivo deste trabalho foi quantificar o cobre em lodo de curtume in natura, comparando o resultado com o parâmetro da legislação vigente (NBR 10004) para identificar se há risco de contaminação ambiental caso o lodo seja disposto no solo.

\section{METODOLOGIA}

As amostras de lodo de curtume foram retiradas do tanque em forma de funil com auxílio de um balde de alumínio. As amostras para análise de cobre foram preservadas em vidros âmbar, não tendo a necessidade de acidificar ou resfriar, de acordo com a NBR 10007, que determina os procedimentos de amostragem, preservação e armazenamento de resíduos sólidos.

As amostras foram enviadas para o laboratório de análises na cidade de Guarulhos São Paulo, certificado para realizar as análises de quantificações de compostos conforme previsto na NBR 10006 que determinam os procedimentos para obtenção dos extratos solubilizados, respectivamente, de resíduos sólidos e semisólidos, como é o caso do lodo de curtume. Os procedimentos citados são de domínio público, podendo ser acessados livremente.

Os extratos foram analisados de acordo com os métodos descritos no Standard Methods for the Examination of Water and Wastewater 21a Edição para análises em espectrometria de Massas com fonte de Plasma de Argônio (ICPMS). Os resultados das análises quantitativas foram comparados com os limites estabelecidos pela NBR 10004 (anexo G da normativa) para amostras solubilizadas.

\section{RESULTADOS}

O lodo do curtume apresenta características físicas e químicas provenientes ao tipo de tratamento que foi empregado no seu processo, nesse caso, o lodo não possui matéria orgânica. No tratamento do efluente da indústria 
que foi coletada a amostras, são utilizadas enzimas que degradam toda matéria orgânica presente no efluente e uma pequena parte de compostos inorgânicos. O efluente do curtume é tratado por meio de fluxo contínuo gerando uma média de $50 \mathrm{~m}^{3}$ de lodo por dia.

A análise quantitativa de cobre presente na amostra de lodo determinou a concentração de 3,926 mg.L'1. O equipamento de espectrômetro de massas possui um limite de quantificação (LQ) de 0,010 mg. $\mathrm{L}^{-1}$.

A NBR 10004 - anexo G permite que o máximo da concentração de cobre para amostras solubilizadas seja $2,0 \mathrm{mg} \cdot \mathrm{L}^{-1}$, portanto a amostra apresenta concentração de cobre acima do que é permitido.

DISCUSSÃO

Os metais apresentam algumas diferenças em relação à concentração que podem ser encontrados naturalmente no solo. De uma forma geral, o ferro e o manganês são os metais mais abundantes nos solos, são nutrientes e apresentam baixa toxicidade. Elementos como o cobalto, cobre, crômio, níquel e o zinco existem em menores concentrações, possuem importância significativa para o meio biótico, mas são tóxicos quando presentes em concentrações elevadas, geralmente originadas por diferentes tipos de atividades antrópicas ${ }^{9}$.

A concentração de cobre acima do permitido pela legislação, presente na amostra de lodo, pode ter origem na utilização de fungicidas e outros compostos a base de cobre durante $o$ processo industrial, a tabela 1 demostra alguns exemplos ${ }^{10}$.

Tabela 1. Compostos a base de cobre mais utilizados em processos industriais.

\begin{tabular}{lcc}
\hline Componente & Fórmula & Usos \\
\hline Sulfato de cobre & $\mathrm{CuSO}_{4}$ & $\begin{array}{c}\text { Algicida, herbicida, tinturaria e grande } \\
\text { variedade de usos industriais }\end{array}$ \\
$\begin{array}{l}\text { Cromato de cobre } \\
\text { Arsenito de cobre }\end{array}$ & $\mathrm{CuCrO}_{4}$ & Fungicida, inseticida e tingimento \\
Acetato de cobre & $\mathrm{CuHAsO}$ & Inseticida, fungicida e pigmentação \\
\hline
\end{tabular}

O cobre é amplamente utilizado como fungicida na agricultura ou como pigmento para fabricação de tintas, estando sempre presente em efluentes industriais e domésticos ${ }^{10}$.

Os fungicidas são muito utilizados no processo de curtimento e preservação das peles, apesar de ser segredo industrial a formula utilizada e a quantidade no processo estudado, sabe-se que o fungicida utilizado é a base de cobre, o que explica a sua presença no efluente, consequentemente no lodo, justificando o teor encontrado.

Após o processo de curtimento, nesta indústria estudada, as peles seguem para o setor de acabamento onde é realizado o tingimento de couro conforme pedido pelo cliente, ou seja, pode ser que haja mais uma fonte de cobre dentro do processo industrial. Supõe que no processo seja utilizada grande quantidade de compostos a base de cobre, o excesso segue para o efluente concentrando no lodo.

\section{CONCLUSÃO}

Pode-se concluir que o teor de cobre está acima do permitido pela legislação, provavelmente, devido ao uso de fungicidas e outros compostos utilizados no processo industrial. Esse lodo pode ser enviado para aterros industriais certificados ou ser tratado, passando por algum processo que diminua a concentração de cobre, tornando-o viável para a aplicação no solo.

\section{CONFLITO DE INTERESSES}

Os autores declaram não haver qualquer potencial conflito de interesses que possa interferir na imparcialidade deste trabalho científico.

\section{REFERÊNCIAS}

1. Sperling, MV. Lodos ativados: Princípios do tratamento biológico de águas reriduárias. 2.ed. Belo Horizonte: UFMG; 1997.

2. Associação Brasileira de Normas Técnicas ABNT: Classificação de resíduos sólidos, NBR 10004 (2004). Procedimento para obtenção do extrato solubilizado de resíduos sólidos, NBR 
10006 (2004). Amostragem de resíduos sólidos, NBR 10007 (2004).

3. Silva DM. Lodo de curtume na composição de substratos para produção de mudas para reflorestamento [Tese]. Presidente Prudente: Universidade do Oeste Paulista, 2012.

4. Araújo FF. Desenvolvimento do milho e fertilidade do solo após aplicação de lodo de curtume e fosforita. Rev Bras Eng Agríc Amb. 2008;12(5):507-11.

DOI: https://doi.org/10.1590/S141543662008000500011.

5. Silva DCS, Leal TTB, Araújo RM, Gomes RLF, Araújo ASF, Melo WJ. Emergência e crescimento inicial de plântulas de pimenta ornamental e celosia em substrato à base de compostos de lodo de curtume. Ciên Rural. 2011;41(3):412-7. DOI: $\quad$ https://doi.org/10.1590/S0103$\underline{84782011000300008}$

6. Martines AM, Andrade CA, Cardoso EJBN. Mineralização do carbono orgânico em solos tratados com lodo de curtume. Pesq Agropec Bras. 2006;41(7):1149-55. DOI: https://doi.org/10.1590/S0100$\underline{204 \times 2006000700011}$

7. Chaves LHG, Mesquita EF, Araujo DL, França CP. Crescimento, distribuição e acúmulo de cobre e zinco em plantas de pinhão-manso. Rev Ciên Agro. 2010;41(2):167-76. DOI: https://doi.org/10.1590/S1806$\underline{66902010000200001}$

8. Boldarine MTB. Avaliação dos efeitos da contaminação de cobre no solo sobre Mentha Crispa L. Paraná: Universidade Tecnológica Federal do Paraná, 2017. Acesso em: 6 Ago 2018. Disponível em: http://riut.utfpr.edu.br/ispui/handle/1/2259

9. Lopes A, Remédios C, Deus C, Barros S. Identificação da presença de bactérias resistentes a metais em solos contaminados por poluição industrial. CAPTAR. 2011;3(2):95-103.

10. Gusmão LFMG. Efeitos do cobre e cromo na comunidade zooplanctônica: um estudo experimental em mesocosmos [Tese]. São Carlos: Universidade de São Paulo, 2004. Acesso em 6 Ago 2018. Disponível em:

Colloq Vitae 2019 mai-ago; 11(2): 1-4.

Artigo Open Access sob uma licença CC BY-NC-ND (http://creativecommons.org/licenses/by-nc-nd/4.0/). http://www.teses.usp.br/teses/disponiveis/18/1 8139/tde-14102004-165206/en.php 